\title{
Mild Hydrothermal Conditioning Prior to Torrefaction and Slow Pyrolysis of Low-value Biomass
}

\author{
reinhart vanpoucke ${ }^{\mathrm{a}^{*}}$, Robert Nachenius ${ }^{\mathrm{a}}$, Kevin Agbo ${ }^{\mathrm{a}}$, Filip Tack $^{\mathrm{a}}$, Yong Sik Ok ${ }^{\mathrm{b}}$, Frederik Ronsse $^{\mathrm{a}}$, Erik \\ Meers $^{\mathrm{a}}$ \\ ${ }^{a}$ Ghent University, Belgium \\ ${ }^{\mathrm{b}}$ Korea Biochar Research Center \& School of Natural Resource and Environmental Sciences, Kangwon \\ National University, Chuncheon 24341, Korea
}

\begin{abstract}
Thermochemical processes such as torrefaction and slow pyrolysis may be used to upgrade low-quality lignocellulosic biomass into superior solid biofuels. Such processes will benefit economically if low-value, feed material (typically non-woody biomass) is used. One of the problems associated with non-woody biomass is the high level of inorganic materials which may need to be reduced by pretreatment to ensure that the solid fuel is acceptable to the end-user. The severity of the thermochemical processes themselves also affect the whether these materials remain in the solid product or not. The thermochemical upgrading of different feed materials (including willow, grasses and grass press cakes generated through mild hydrothermal conditioning and mechanical dewatering) has been investigated via batch experiments and product analyses. It was found that torrefaction and slow pyrolysis are suitable means for increasing the quality of the biomass (in terms of higher heating value) but that slow pyrolysis is only beneficial when the biomass has a low ash content. Hydrothermal conditioning was used to reduce the ash content while specifically reducing the nitrogen, potassium and the chlorine in the biomass. Torrefaction and slow pyrolysis are able to remove some of the nitrogen present in the biomass (in addition to reducing oxygen and hydrogen content) but other elements were generally concentrated through the solid mass loss associated with torrefaction and slow pyrolysis. Hydrothermal conditioning and subsequent slow pyrolysis of low-value residual grass resulted in a product comparable to volatile bituminous coal.
\end{abstract}

\footnotetext{
* Corresponding author. Ghent University, Belgium. Email address: reinhart.vanpoucke@ugent.be
} 